\title{
Robin T. Bowen: Ethics and the practice of forensic science
}

\author{
CRC Press, 2010, pp. 217, hardback, ISBN 978-1-4200-8893-9
}

\author{
Jeffrey P. Walterscheid
}

Published online: 16 November 2010

(C) Springer Science+Business Media, LLC 2010

Forensic analysis requires a great deal of understanding, education, training and skill. The scientists who practice within this profession often encounter an uncomfortable proximity with crime, violence, and death as part of their daily workload. Because of the urgency and difficulty of this environment, there is a potential for dishonesty through political issues, high stress, and personal bias. While the law describes the course of actions one must follow, ethics are standards of conduct that prescribe behavior out of obligation, honor, and duty, which are validated by fairness and consistency.

Ethical decisions require people to reconcile their behaviors, principles, and goals. Everyone is human, and all humans make mistakes. However, a deceitful analyst who issues a falsified report betrays the trust of the public, undermines fellow professionals, and jeopardizes justice. One of the most effective ways to guard against ethical misconduct is to maintain an awareness of paths to wrongdoing. This book is a fantastic resource to keep readers familiar with potential issues, how to avoid them, and how to manage the problems that do occur before they escalate.

The author begins at the roots of ethical behavior through comparing and contrasting the philosophic principles of deontological ethics, existentialism, determinism, and intentionalism. At first, these topics may seem overwhelming or dull, but the ideas are distilled and presented in a palatable context such as "doing what makes you happy is not as important as doing what makes you worthy of happiness. Emotion is not a good indicator for ethical

J. P. Walterscheid (凶)

Harris County Institute of Forensic Sciences, 1885 Old Spanish

Trail, Houston, TX, USA

e-mail: jeffrey.walterscheid@ifs.hctx.net decisions because sometimes what is right does not feel good or make us happy."

These concepts are incorporated into a foundation for further inspections of moral behaviors in sensitivity, judgment, motivation, and character. As each facet is explored, the reader should easily realize a connection to personal experiences whether one is involved in DNA, toxicology, or fingerprint analysis. This approach establishes a framework for the reader to apply ethical decision-making by rejecting dogmatic principles, remaining sensitive to alternate perspectives, being aware of what is truth and what is a lie, and taking pride in doing a good job for its own sake.

In order to form a coherent and disciplined style of behavior, one must also be aware of the paths to avoid. The author devotes a great deal of content to identifying the main types of unethical behavior in criminal justice such as deception, prejudice, and egoism. These traits tend to promote opportunities and incentives for corruption, as in matters of misrepresenting the facts while interpreting evidence or exaggerating credentials for expertise. In depth discussions of the Duke Lacrosse rape case, the O. J. Simpson trial, and various crime lab debacles are used to highlight ethical failures in maintaining the integrity of proper forensic procedures.

In summary, this book is a modern and relevant guide for forensic analysts, experts, law enforcement, and attorneys in maintaining an appreciation for good ethics. Among the recommendations and examples given, the text also contains a centralized collection of ethics codes provided by ASCLD, AAFS, and other professional forensic organizations. An attached appendix shares results from an ethics survey gathered from the 2006 AAFS meeting. The responses reveal humorous, shocking, and thought-provoking insight into the intricate struggle to sustain a comprehensive and uniform practice of ethics in forensic science. 